\title{
Impact of Instant Wheat Meal Supplementation and Nutrition Counselling On Anthropometry and Blood Pressure of Non Insulin Dependent Diabetics
}

\author{
Anita Kochhar, Kanchandeep Gulati and Rajbir Sachdeva \\ Department of Food and Nutrition, College of Home Science, Punjab Agricultural University \\ Ludhiana. Punjab, India \\ E-mail: dranitakochhar@yahoo.com
}

KEYWORDS Anthropometric Parameters. Blood Pressure. Instant Wheat Meal Non Insulin Dependent Diabetes Nutrition Counselling

\begin{abstract}
Thirty non insulin dependent diabetic females of 40-60 years were selected from Punjab Agricultural University Hospital, Ludhiana. General information and family history of the subjects was recorded by interview schedule. After one month control period, $125 \mathrm{~g}$ of instant wheat meal $(45 \mathrm{~g}$ in breakfast, $40 \mathrm{~g}$ in mid morning and $40 \mathrm{~g}$ in evening tea was given daily to the selected subjects. Instant wheat meal was given to all the subjects on weekly basis for a period of two months to study the impact of instant wheat meal supplementation and nutrition counselling on anthropometry and blood pressure of non insulin dependent diabetics. The body weight, BMI and waist hip ratio reduced significantly but were still higher than the recommended standard after supplementation. Significant decrease in blood pressure of the subject was also recorded after supplementation of instant wheat meal. It can be inferred from the results that supplementation of instant wheat meal helped in the reduction of anthropometric parameters and blood pressure of the diabetic subjects and thus helped in the retardation of secondary complications.
\end{abstract}

\section{INTRODUCTION}

Diabetes mellitus is a silent chronic disorder characterized by elevated blood sugar level either due to defective insulin secretion or action or both. It is associated with altered metabolism of carbohydrates, fats and protein.

Diabetes is believed to have strong genetic factor and this is usually seen in people with a family history of diabetes. At the onset, diabetes is a silent disorder but as it progresses it can cause damage to many part of the body systems especially the blood vessels and nerves. It is leading cause of blindness, kidney failure, foot ulcers and impotency (Jain 2003).

Many recent studies have high lighted the hypocholesterolemic effect of soy and its products. Soy fibres have been shown to improve glucose tolerance and insulin response in diabetic patients besides providing low cost high quality nutrients to needed population in developing countries (Kavitha et al. 2001). Anderson and Major (2002) suggested hypocholesterolaemic effects of pulses appear related in estimated order of importance to these factors, soluble dietary fibre, vegetable protein, oligosaccharides, isoflavones phospholipids and fatty acids. Intake of pulses may also reduce the risk for cardiovascular disease by favourable effects on blood pressure, glycaemia and risk of diabetes.
Most of the people though educated are quite ignorant about the impact of diet on diabetes. The two major goals of management of non insulin dependent diabetes mellitus are to achieve the metabolic control near normal and to prevent or delay the microvascular complications of diabetes.

So keeping in view the beneficial effect of soybean for diabetics the present study was planned to see the impact instant wheat meal supplementation and nutrition counselling on anthropometry and blood pressure of non insulin dependent diabetics.

\section{MATERIAL AND METHODS}

Selection of Subjects: A sample of 30 non insulin dependent female diabetics aged 40-60 years were selected from Punjab Agricultural University Hospital, Ludhiana. General information of the subjects was recorded by interview schedule.

Preparation of the Product: Instant wheat meal was prepared by mixing $100 \mathrm{~g}$ of wheat flour with $25 \mathrm{~g}$ of soyabean flour in the ratio fo $4: 1$ with the help of super allegro foods.

Feeding of Subjects: The subjects were followed for one month period and no treatment was given during this period except the pres- 
cribed medicine which they were already taking and after one month period, $125 \mathrm{~g}$ of the prepared instant wheat meal (45 $\mathrm{g}$ in the breakfast, $40 \mathrm{~g}$ in mid morning and $40 \mathrm{~g}$ in the evening tea) was given daily to the selected subjects. Feeding was done for the two months. This instant wheat meal was distributed to the patients on weekly basis to ensure regular consumption as per instructions given to them. Along with feeding nutrition education was also imparted regarding the disease and benefits of soyabean through pamphlets which were distributed among all the subjects.

Nutrition Counselling: Nutrition education was given to all the subjects for a period of 3 months at a interval of 15 days. Education regarding diabetes, types of diabetes, the causes, symptoms, complications, dietary management and benefits of soyabean was imparted to the patients through lecture cum demonstration method. Personal contact with respondents was maintained throughout the study period to solve their personal queries.

Anthropometric Parameters: The height, weight, mid upper arm circumference, TSFT of the subjects was measured before and after experimental period according to the method given by Jelliffe (1966). The body mass index (BMI) of the subjects was calculated using formulae weight in kilogram/ height in meter square.

Blood Pressure: Blood pressure of the subjects was recorded before and after experimental period with sphigmo manometer by physician (Maclead 1984).

Statistical Analysis: The data on anthropometric measurements, blood pressure of the subjects was analysed statistically. The mean, standard error, t-value and their test of significant was calculated using a computer programme package (Cheema and Singh 1990).

\section{RESULTS AND DISCUSSION}

The general information of the subjects is given Table 1 . The subjects selected for the study were in the age group of 40-60 years comprising $19(63 \%)$ between $40-50$ years and $11(37 \%)$ between 50-60 years. Majority of the subjects $80 \%$ were Hindu and $20 \%$ were sikhs. Out of all the subjects, 37 per cent were educated upto high school, $30 \%$ were graduate, while $20 \%$ were illiterate and $13 \%$ were educated upto middle class.
Majority of the females were housewives (80\%) and $20 \%$ were engaged in service. Majority of the subjects $(93 \%)$ had a sedentary life style and $7 \%$ were engaged in moderate activity. Yaznik (2004) suggested that urban life style, including poor diet, sedentary habits promote obesity, insulin resistance and type II diabetes. It was found that $70 \%$ of the subjects were from nuclear families and $30 \%$ were from joint families. Thirty per cent of the subjects belonged to families of 14 members, 50\% having 5-8 members and $20 \%$ having more than 8 members.

Distribution of the subjects according to their income status is presented in Table 2. The average monthly income was Rs. 9677/- per family with per capita income of Rs. 2230/-.

\section{Diabetic Information of the Subjects}

Table 3 depicts the signs and symptoms of diabetes among subjects. The most common signs were polydypsia, tiredness and polyphagia. Some of other symptoms were polyurea, headache, excessive sweating, burning sensation and weight loss. The occurrence of symptoms in decreasing order of frequency were polydypsia $(80 \%)$, tiredness $73 \%$, polyphagia $(67 \%)$ polyurea $43 \%$, burning sensation in feet $20 \%$ excessive sweating $(17 \%)$, headache $13 \%$ and weight loss $(7 \%)$.

Table 1: General information of the subjects $(n=30)$

\begin{tabular}{lrc}
\hline General & \multicolumn{2}{c}{ Subjects } \\
\cline { 2 - 3 } & No. & Percentage \\
\hline Age & 19 & 63.0 \\
$\quad 40-50$ & 11 & 37.0 \\
$\quad 50-60$ & 24 & 80.0 \\
Religion & 6 & 20.0 \\
$\quad$ Hindu & & \\
$\quad$ Sikh & 6 & 20.0 \\
Education & 4 & 13.0 \\
$\quad$ Illiterate & 11 & 37.0 \\
$\quad$ Primary to middle & 9 & 30.0 \\
$\quad$ High school & & \\
$\quad$ Graduate & 24 & 80.0 \\
Occupation & 6 & 20.0 \\
$\quad$ Housewife & & \\
$\quad$ Service & 28 & 93.0 \\
Activity & 2 & 7.0 \\
$\quad$ Sedentary & & \\
$\quad$ Moderate & 21 & 70.0 \\
Family Type & 9 & 30.0 \\
$\quad$ Nuclear & & \\
$\quad$ Joint & 9 & 30.0 \\
Family Size & 6 & 50.0 \\
$\quad$ Small (1-4) & 20.0 \\
$\quad$ Medium (5-8) & Large (>8) &
\end{tabular}


Table 2: Economic status of the subjects $(n=30)$

\begin{tabular}{lcc}
\hline Economic status & \multicolumn{2}{c}{ Subjects } \\
\cline { 2 - 3 } & No. & Percentage \\
\hline Family Income/Month (rs.) & 5 & 17.0 \\
$\quad \leq 6000$ & 3 & 10.0 \\
$6000-8000$ & 3 & 10.0 \\
$8000-10000$ & 19 & 63.0 \\
$\geq 10000$ & & \\
Per Capita Income/Month (Rs.) & 6 & 20.0 \\
$\quad$ 1000-1500 & 3 & 10.0 \\
$1500-2000$ & 4 & 13.0 \\
$2000-2500$ & 17 & 57.0 \\
$\geq 2500$ & & \\
Family Income (Rs.) & & \\
$\quad$ Mean 9677.5 & & \\
S.E. \pm 590.5 & & \\
Per Capita Income (Rs.) & \\
$\quad$ Mean 2230.3 & & \\
S.E. \pm 112.29 & & \\
\hline
\end{tabular}

Table 3: Signs and symptoms of diabetes among subjects $(\mathbf{n}=\mathbf{3 0})$

\begin{tabular}{lrc}
\hline Symptoms & \multicolumn{2}{c}{ Subjects } \\
\cline { 2 - 3 } & No. & Percentage \\
\hline Polydypsia & 24 & 80.0 \\
Polyuria & 13 & 43.0 \\
Polyphagia & 20 & 67.0 \\
Tiredness & 22 & 73.0 \\
Weightloss & 2 & 7.0 \\
Excessive sweating & 5 & 17.0 \\
Headache & 4 & 13.0 \\
Delayed healing & 0 & 0.0 \\
Burning sensation in feet & 6 & 20.0 \\
\hline
\end{tabular}

Family history of the diabetes was recorded and it was observed that $53 \%$ of the subjects had a positive family history with either a single parent $(23 \%)$ or both parents $(10 \%)$ siblings $(17 \%)$ or in any other relative $3 \%$ (Table 4 ). According to Warram et al. (1990) off spring of diabetes parents had slower glucose removal rates and higher insulin level than control subjects suggesting that primary defect is in peripheral tissue response to insulin and glucose. Genetically, Indians are prone to the insulin resistance syndrome, which is caused by abdominal fact, thin arteries and high blood pressure (Jain 2003).

Table 4: Family history of diabetes among subjects $(\mathbf{n}=\mathbf{3 0})$

\begin{tabular}{lrc}
\hline Relation & \multicolumn{2}{c}{ Subjects } \\
\cline { 2 - 3 } & No. & Percentage \\
\hline Family history & 16 & 53.0 \\
Single parent & 7 & 23.0 \\
Both & 3 & 10.0 \\
Siblings & 5 & 17.0 \\
Any other relative & 1 & 3.0 \\
\hline
\end{tabular}

\section{Frequency of Food Consumption}

Frequency of consumption of various foods by the subjects before the onset of the disease were studied to correlate dietary factors of subjects acquiring the disease (Table 5).

Wheat and rice were the major source of cereals. The use of refined cereals was not common among the subjects. Thirty per cent subjects never consumed these in any period of their life. Unrefined cereals had been their staple diet with an intake of thrice/day in 90 per cent subjects while the rest had consumed once or twice/day. Pulses were consumed daily by $33 \%$ of the subjects whereas $43 \%$ of the subjects consumed thrice a week. The intake of green leafy

Table 5: Frequency of food consumption before onset of the disease $(n=30)$

\begin{tabular}{|c|c|c|c|c|c|c|c|c|c|c|}
\hline \multirow[t]{2}{*}{ Food items } & \multicolumn{4}{|c|}{ No. of times/day } & \multicolumn{4}{|c|}{ No. of items/week } & \multirow{2}{*}{$\begin{array}{c}\text { Occa- } \\
\text { sionally }\end{array}$} & \multirow{2}{*}{$\begin{array}{l}\text { Not } \\
\text { at all }\end{array}$} \\
\hline & 4 & 3 & 2 & 1 & 4 & 3 & 2 & 1 & & \\
\hline \multicolumn{11}{|l|}{ Cereals } \\
\hline a) Unrefined & 0 & 90 & 6.7 & 3.3 & 0 & 0 & 0 & 0 & & \\
\hline b) Refined & 0 & 0 & 0 & 10 & 13.33 & 0 & 26.66 & 10 & 10 & 30 \\
\hline \multicolumn{11}{|l|}{ Pulses } \\
\hline a) Whole & 0 & 0 & 10 & 33.3 & 6.7 & 43.3 & 6.7 & 0 & 0 & 0 \\
\hline b) Split & 0 & 0 & 3.33 & 20 & 20 & 53.33 & 0 & 0 & 3.33 & 0 \\
\hline GLV & 0 & 0 & 3.33 & 6.66 & 6.66 & 13.33 & 20 & 50 & 0 & 0 \\
\hline $\mathrm{R} / \mathrm{T}$ & 0 & 16.66 & 33.3 & 50 & 0 & 0 & 0 & 0 & 0 & \\
\hline Fruits & 0 & 0 & 0 & 33.33 & 3.33 & 13.33 & 6.66 & 43.33 & 0 & 0 \\
\hline Milk products & 0 & 0 & 10 & 83.33 & 6.66 & 0 & 0 & 0 & 0 & 0 \\
\hline Sweets & 0 & 0 & 13.33 & 26.66 & 33.33 & 10 & 10 & 3.33 & 3.33 & 0 \\
\hline Fried foods & 0 & 0 & 0 & 33.33 & 0 & 50 & 10 & 3.33 & 3.33 & 0 \\
\hline
\end{tabular}

Values are given in percentages 
vegetables was in winter. Fifty per cent were taking once a week and $20 \%$ twice a week and $13 \%$ thrice a week. Fifty percent of the subjects consumed roots and tubers once a day and $33 \%$ consumed twice a day either in the form of vegetable curry or snack. About $33 \%$ of the subjects consumed fruits once a day, and $43 \%$ consumed once a week and rest consumed twice or thrice a week. Consumption of milk and milk products by the subjects was $83 \%$ once daily and $10 \%$ twice a day and was mainly in the form of tea and curd. A total of $26 \%$ of the subjects had consumed sweets once a day and $13 \%$ twice a day. About $33 \%$ four times a week and rest twice and thrice a week. The most common fried products which were consumed were potato tikkies and samosas. Fifty percent thrice a week and rest once or twice a week.

\section{Anthropometric Parameters}

The anthropometric parameters like height, weight, body mass index (BMI), mid upper arm circumference (MUAC), tricep skinfold thickness (TSFT) and waist hip ratio is presented in Table 6. The mean height of the subjects before and after feeding ranged from 148.5 to 157.5 with the mean value of $155 \pm 0.66 \mathrm{~cm}$. The average weight of the subjects before and after feeding ranged from 54 to $84 \mathrm{~kg}$ and 50 to $80 \mathrm{~kg}$ respectively. The corresponding mean value before and after feeding were $71.73 \pm 1.59 \mathrm{~kg}$ and $66.02 \pm 1.42 \mathrm{~kg}$. The average weight after feeding decreased significantly $(\mathrm{P} \leq 0.01)$ which can be due to reduction in energy intake. Sadana and Hira (1997) stated that socio-economic status and income were also found to be factors which clearly influence the body weight and height.

A derived index of fatness form weight and height was used to classify the subjects into grades of obesity (Table 7) according to classification proposed by James et al. (1988). The percentage of severely overweight subjects reduced from 63 to $30 \%$ after supplementation of instant wheat meal. On the other hands there was no change in the acceptable weight whereas the moderate weight increased from 23 to $56 \%$. While in the category of underweight there was no subject. The range in BMI of the subjects before and after feeding was 22.5 to $34.5 \mathrm{~kg} / \mathrm{m}^{2}$ and 22.7 to $31.4 \mathrm{~kg} / \mathrm{m}^{2}$. The corresponding mean value before and after feeding was $29.89 \pm 0.70 \mathrm{~kg} / \mathrm{m}^{2}$ and

Table 6: Major anthropometric measurements of the subjects

\begin{tabular}{lccrc}
\hline Variables & Before supplementation & After supplementation & t-value & Reference standard \\
\hline Height & $155 \pm 0.66$ & $155 \pm 0.06$ & - & NA \\
Weight & $71.73 \pm 1.59$ & $66.02 \pm 1.42$ & $3.69 * * *$ & $55^{1}$ \\
BMI & $29.89 \pm 0.70$ & $27.50 \pm 0.63$ & $2.58^{*} * *$ & $20-258^{2}$ \\
MUAC & $28.91 \pm 0.77$ & $28.28 \pm 0.78$ & $0.47^{\mathrm{NS}}$ & $28.5^{3}$ \\
TSFT & $25.51 \pm 1.09$ & $25.30 \pm 1.03$ & $0.96^{\mathrm{NS}}$ & $16.5^{4}$ \\
WHR & $0.89 \pm 0.008$ & $0.84 \pm 0.012$ & $2.69^{*} * *$ & $0.8^{5}$
\end{tabular}

1 Raghuram et al. (1993) 2 James et al. (1988) 3 Jelliffee (1966) 4 Jelliffee (1966) 5 Ghafoorunissa (2000*)

*Significant at 5\% ***Significant at $1 \%$ NS Non-significant NA Data not available

Table 7: Distribution of subjects according to grades of obesity

\begin{tabular}{llcccr}
\hline BMI & Interpretation of BMI & \multicolumn{2}{c}{ Before supplementation } & & \multicolumn{2}{c}{ After supplementation } \\
\cline { 3 - 4 } \cline { 5 - 6 } & & No. & \%age & & No. \\
\hline$<20$ & Underweight & 0 & 0 & 0 & 0.00 \\
$20-25$ & Acceptable weight & 4 & 13.33 & & 13.33 \\
$25-30$ & Moderate weight & 7 & 23.33 & & 17 \\
$>30$ & Severe overweight & 19 & 63.34 & 9 & 36.66 \\
\hline
\end{tabular}

Classification proposed by James et al. (1988)

Table 8: Mean blood pressure of the subjects before and after supplementation

\begin{tabular}{lcccc}
\hline Blood pressure $(\mathrm{mmHg})$ & Before supplementation & After supplementation & t-value & Reference Standard \\
\hline Systolic & $154 \pm 1.93$ & $130 \pm 1.59$ & $4.21 * * *$ & $<120$ \\
Diastolic & $92 \pm 1.84$ & $84 \pm 1.24$ & $4.02 * * *$ & $<80$ \\
\hline
\end{tabular}

*Raghuram et al. (1993)** Significant at $1 \%$ 
$27.5 \pm 0.63 \mathrm{~kg} / \mathrm{m}^{2}$. Decrease in BMI after feeding was found to be statistically significant $(\mathrm{P} \leq 0.01)$ and can be attributed to weight reduction. However, the value was marginally higher than the recommendations. Kamayika et al. (1994) in their study found that BMI of more or equal to 25 was associated with high blood pressure.

The average MUAC of the subjects before feeding ranged from 20.5 to $36.5 \mathrm{~cm}$ with mean value $28.9 \pm 0.77 \mathrm{~cm}$. After feeding, the value of MUAC ranged from 20 to $35 \mathrm{~cm}$ with mean value $28.28 \pm 0.78 \mathrm{~cm}$. MUAC values were higher when compared with desirable values reported by Jelliffe (1966). Non significant decrease in MUAC was observed.

The mean TSFT of the subjects ranged from 12 to $35.5 \mathrm{~cm}$ before supplementation, whereas after supplementation the value ranged from 12 to $35 \mathrm{~mm}$. The corresponding mean value before and after feeding was $25.51 \pm 1.09 \mathrm{~mm}$ and $25.30 \pm 1.03 \mathrm{~mm}$ respectively. TSFT value was higher than recommendations. Decrease in TSFT values after supplementation was statistically non significant. On the contrary reduction in TSFT among type II Japanese-American women was reported by Liao et al. (2002).

The average waist hip ratio of the subjects ranged from 0.80 to 1.04 before freeding while after feeding, the value ranged from 0.80 to 1.0 . Waist hip ratio was an higher side when compared with recommendation. The average waist hip ratio was decreased significantly $(\mathrm{P} \leq 0.01)$ which may be due to reduction in body weight. Gupta and Majumdar (1994) suggested that increased abdominal adiposity is associated with cardiovascular risk factors.

\section{Blood Pressure}

The mean blood pressure of the subjects before and after supplementation is presented in Table 8 . The average systolic blood presusre of the subjects ranged from 134 to $158 \mathrm{~mm} \mathrm{Hg}$ before supplementation while after supplementation, it ranged from 120 to $140 \mathrm{mmHg}$. The corresponding mean values before and after supplementation were $154 \pm 1.93 \mathrm{~mm} \mathrm{Hg}$ and $130 \pm 1.59 \mathrm{mmHg}$ respectively. Decrease in systolic blood pressure after supplementation was statistically significant $(\mathrm{P} \leq 0.01)$ but still higher than the desirable level. The average diastolic blood pressure before supplementation ranged from 80 to $110 \mathrm{~mm} \mathrm{Hg}$ with mean value of $92 \pm 1.84 \mathrm{mmHg}$. After supplementation, the value ranged from 80 to 100 $\mathrm{mmHg}$ with mean value of $84 \pm 1.24 \mathrm{mmHg}$. Decrease in diastolic blood pressure after supplementation was significant $(\mathrm{P} \leq 0.01)$. However, the values are higher than the desirable value reported by Raghuram et al. (1993). Jenkins et al. (2002) had also reported significant decrease in systolic and diastolic blood pressure after ingestion of soya diet with in one month. On the contrary, Tonstead et al. (2002) did not observe any significant change in blood pressure after taking soya rich diet.

\section{CONCLUSION}

Hence it was concluded from the study that supplementation of instant wheat meal prepared by mixing $100 \mathrm{~g}$ of wheat flour and $25 \mathrm{~g}$ of defatted soyabean flour in the ratio of 4: 1 in the diets of diabetic patients helped in the reduction of their anthropometric parameters and blood pressure.

\section{REFERENCES}

Anderson JW, Major AW 2002. Pulses and lipaemia, short and long term effect: Potential in the prevention of cardiovascular disease. J Nutr, 88: 5263-5271.

Cheema HS, Singh B 1990. CPCSI - A Computer Programme Package for the Analysis of Commonly Used Experimental Design. Ludhiana: Punjab Agricultural University.

Ghafoorrunissa, Krishnaswamy M 2000. Diet and Heart Disease. Hyderabad: National Institute of Nutrition (ICMR).

Gupta R, Majumdar S 1994. Correlation of waist hip ratio with coronary heart disease and risk factors prevalent in rural population. India Heart J, 46: $145-148$.

Jain M 2003. Diabetes striking the young. India Today, April 1999

James WPT, Ferro-Luizzi, Waterlow JC 1988. Definition of chronic energy deficiency in adults - Report of working party of intervention dietary energy consultation group. Am J Clin Nutr, 42: 969-981.

Jenkins DJA, Kendal CWC, Jackson CC, Connelly PW, Parker T, Fualken D, Vidgen E, Robert RG 2002. Effect of high and low isoflavonessay foods on blood lipids, oxidized LDL, hamosystem and blood pressure in hyperlipidemia men and women, Am J Clin Nutr, 76: $365-372$.

Jelliffe DB 1966. The Assessment of Nutritional Status of the Community. World Health Organisation Monograph Series No. 53, Geneva: WHO, pp. 5084.

Kamayika K, Viedananam, Reilly O 1994. Antioxidant action and potential antidiabetic properties of an isoflavonoid containing soyabean. Phytotherapy Research, 13: 601-608.

Kavitha P, Parvathii EP, Uma MS 2001. Effect of different 
methods of cooking on dietary fibre content of wheat and wheat products and hypoglycemic effect on NIDDM patients. Ind J Nutr Dietet, 38: 173-181.

Liao MV, Shanthiram CS, Deepa R 2002. Glucose intolerance. J Assoc Physicians India, 51: 756-757.

Maclead J 1984. Davidsons Principles and Practice of Medicine. 14th Ed., Churchhill Livingstone: ELBS,

Raghman TC, Pasricha S, Sharma RD 1993. Diet and Diabetes. Hyderabad: National Institute of Nutrition (ICMR).

Sadana B, Hira CK 1997. Effect of income and season on the nutrient intake of rural women in central plain zone and Kandi area of Punjab. Ind J Reol, 24: 66-74.
Tonstead S, Smerud K, Hore L 2002. A comparison of the effects of 2 doses of soy protein or casein on serum lipids, serum lipoprotein and plasma total hamocystine in hypercholesterolemic subjects. Am J Clin Nutr, 76: 78-84.

Warram JH, Martin BC, Krolenstci AS, Sodender JS, Kahn CR 1990. Mean basal glucose removal rate and hyper insulinemia precede the development of type II diabetes in the offspring of diabetic patients. Annals of International Medicine, 113: 909-915.

Yaznik CS 2004. Rarely life origin of insulin resistance and type 2 diabetes in India and other Asian Countries. J Nutr, 134: 205-210. 